\title{
O PAPEL DOS CORPORA NA ANÁLISE DO COMPORTAMENTO LINGUÍSTICO DE TRADUTORES PROFISSIONAIS ${ }^{2} 2$
}

\author{
de Mona Baker, Centre for Translation Studies, UMIST
}

\author{
Talita Serpa \\ Universidade Estadual Paulista Júlio de Mesquita Filho (UNESP), Brasil \\ talitasrp82@gmail.com \\ Diva Cardoso de Camargo \\ Universidade Estadual Paulista Júlio de Mesquita Filho (UNESP), Brasil \\ divaccamargo@gmail.com
}

DOI: https://doi.org/10.26512/caleidoscopio.v3i2.26220

Recebido em: 17/07/2018

Aceito em: 07/11/2019

Publicado em dezembro de 2019

\begin{abstract}
RESUMO: 0 Translational English Corpus (TEC) hospedado pelo Centre for Translation Studies do The University of Manchester Institute of Science and Technology (UMIST) é uma coleção informatizada de traduções autênticas realizada por uma vasta gama de tradutores profissionais, tendo como língua de chegada (LC) o inglês; e partindo de uma ampla variedade de línguas de partida (LP). Essa fonte de dados fornece a base para investigar questões relacionadas com as distintas naturezas do texto traduzido (TT), bem como com o estilo individual do tradutor, o impacto dos idiomas de origem sobre a padronização do inglês, a influência do tipo de textos sobre as estratégias de tradução e outros temas de interesse para os Estudos da Tradução e para a Linguística. Mais importante ainda, este recurso concreto permite-nos desenvolver uma estrutura para o estudo da validade das declarações teóricas sobre a natureza da Tradução ${ }^{3}$, com referência à prática tradutória real.
\end{abstract}

Palavras-chave: Estudos da Tradução. Tradução para o inglês. TEC. Linguística de Corpus. Estratégias de Tradução.

\footnotetext{
${ }^{1}$ Artigo publicado na revista International journal of corpus linguistics em 1999. A presente tradução foi autorizada para ser publicada em português pela Editora John Benjamins Publishing Company ( $<$ https://benjamins.com/>) e pela autora, Mona Baker, aos quais agradecemos imensamente. Referência bibliográfica completa do artigo original: BAKER, Mona. The role of corpora in investigating the linguistic behaviour of professional translators. International journal of corpus linguistics, v. 4, n. 2, p. 281-298, 1999. ${ }^{2}$ Este texto apresenta algumas informações marcadas por sua temporalidade. A Linguística de Corpus assumiu papel crucial no desenvolvimento dos Estudos da Tradução promovidos por Mona Baker. Acreditamos, contudo, que suas tradução pode trazer benefícios para a compreensão das proposições da autora e dos demais pesquisadores da linha, os quais tomam tais premissas como norteadoras de suas análises.

${ }^{3}$ Faremos a distinção entre tradução (produto) e Tradução (área do saber, Ciência).
} 


\section{Introdução}

A aplicação das tecnologias com base em corpus e de suas análises no campo dos Estudos de Tradução ainda está em sua infância. 0 trabalho nesta área começou de forma exploratória no início dos anos 90 e só agora começa a produzir alguns resultados concretos, embora em uma escala relativamente pequena (LAVIOSA, 1996; KENNY, 1999; BAKER; 1995; OLOHAN, BAKER, 20004). Isso pode parecer estranho, uma vez que a Tradução é uma atividade linguística que deve interessar aos linguistas de corpus e que a Linguística de Corpus oferece aos estudiosos da Tradução um poderoso conjunto de ferramentas que já revolucionaram o estudo da linguagem em outras esferas.

Há, talvez, duas razões principais para o fato de a Linguística de Corpus não ter tido mais impacto nos Estudos da Tradução até agora. Um motivo diz respeito à imagem negativa que a Linguística Tradicional, desenvolvida dentro dos Estudos de Tradução (durante os anos 80 e 90), depois de várias décadas de teorizações simplistas, criou a respeito do fenômeno da Tradução, o que levou os estudiosos a se concentrarem em estruturas formais e a falharem em relacionar padrões linguísticos ao seu uso por tradutores, bem como ao contexto ideológico ao qual estão atrelados (BAKER, 1996a, 1999). A segunda razão, e, por vezes, a mais importante, é a atitude tradicional dos linguistas de corpus mediante o texto traduzido (TT).

Os linguistas de corpus têm tradicionalmente excluído as traduções de suas coleções de textos, com base no facto de não serem representativas da língua em estudo. Isto, por si só, pode muito bem ser uma decisão válida e, de alguma forma, apoiar o impulso de muito trabalho baseado em corpus no âmbito dos Estudos de Tradução atuais. Estudiosos da Tradução que trabalham nesta área argumentam que o TT tem de ter a sua própria padronização de características devido ao peculiar conjunto de restrições sob as quais é produzido, incluindo o fato de que é limitado por um texto totalmente articulado em outro idioma e de que as traduções têm um diferente status social e textual (as pessoas se relacionam com um TT partindo de um conjunto específico de expectativas). Não é tanto pelo fato de que os linguistas excluem as traduções de seus corpora, o que já é algo problemático, mas sim pelas afirmações categóricas que fazem a respeito de traduções no intuito de justificar a sua decisão de

\footnotetext{
${ }^{4} \mathrm{Na}$ época da publicação o texto estava no prelo.
} 
excluí-las, e também porque veem as traduções não como "diferentes", mas como "desviantes", como se houve algum tipo de norma que o TT fosse inerentemente incapaz de seguir, mas que, no entanto, mantivesse a esperança de alcançar em algumas mundo ideal.

Exemplos desta atitude negativa em relação à Tradução abundam na literatura. John Sinclair, por exemplo, defende o uso de um corpus comparável de textos originais (TOs) em diferentes línguas, porque evita "o inevitável desvio introduzido pelas traduções de um corpus paralelo" (Eagles Web Site; recomendações preliminares sobre a tipologia de corpus, 1996; grifo nosso). Mesmo os estudiosos da Linguística Contrastiva que utilizam corpora paralelos e trabalham deliberadamente com TTs fazem declarações altamente depreciativas sobre os dados que escolheram utilizar. Eis um exemplo recente, que não é, de modo algum, atípico do tipo de atitude esquizofrênica que os linguistas às vezes adotam

O fato de que um corpus de tradução contém combinações perfeitas não implica, infelizmente, que ele também seja uma ferramenta de pesquisa perfeita para linguistas que querem comparar duas ou mais línguas. Um fator intrusivo em tais corpora é a atividade tradutória em si, a qual pode afetar os textos da língua de chegada (AARTS. 1998, p. 9-10 grifo nosso).

Os linguistas da Análise Contrastiva querem usar corpora de TPs e suas respectivas traduções porque estes lhes dão, em teoria, combinações perfeitas. Contudo, ao herdarem a visão tradicional sobre Tradução como sendo algo "distorcido" e "desviante", estudarão TTs não como um registro de atividades linguísticas que será valioso a sua análise, mas sim como um meio para alcançar algo além, a que o linguística não tem acesso devido à natureza dos dados que está verificando, que, por sua vez, se coloca como obstáculo.

Há uma grande diferença entre a atitude do linguista, que vê a atividade de tradução como intrusiva e desviante, e a atitude do estudioso de Tradução, que se propõe especificamente a construir um corpus de TTs, a fim de investigar os padrões distintivos da tradução. Este último não vê o padrão distintivo da tradução como intrusivo e não vê as traduções como contaminando a linguagem "original" ou assim chamada "autêntica" de qualquer forma. 0 estudioso da Tradução vê as traduções como 
verdadeiras instâncias de comunicação que são, de fato, diferentes da chamada escrita original, não por serem corruptas de alguma forma, mas porque funcionam num contexto diferente de produção e recepção. Uma analogia útil pode ser elaborada (até certo ponto) com a diferença entre linguagem falada e escrita: a linguagem falada é diferente da linguagem escrita não porque é "desviante", mas porque ocorre em tempo real e responde a diferentes tipos de pressões cognitivas e sociais ${ }^{5}$. Linguistas felizmente deixaram de falar da língua falada como "inferior" e "subpadrão" há muito tempo, pelo menos no Hemisfério Ocidental6.

\section{Estudando a linguagem da Tradução: 0 Translational English Corpus}

Se aceitarmos que o TT é "diferente", mas não "desviante", e que é uma variedade de uso da linguagem que está sujeita a um conjunto único de restrições e que vale a pena ser estudando em si mesmo, parece razoável investir na construção de um corpus que seja representativo desta variedade e que proceda ao desenvolvimento de uma metodologia para a observação desse corpus. Um corpus de inglês traduzido já existe de fato, como descrito, e está em curso um trabalho para construir um corpus semelhante de finlandês traduzido na School of Translation Studies, Joensuu University, na Finlândia7. Vou primeiramente descrever de maneira abreviada o projeto do Translational English Corpus hospedado no UMIST e, então, discutir, em termos gerais, o tipo de questões para as quais os estudiosos da Tradução podem procurar respostas por meio da análise desse corpus. Em outras palavras, tentarei delinear um vasto programa de investigação para os Estudos da Tradução Baseados em Corpus. Questões de método, em termos de fazer perguntas operacionais de maneira específica, têm sido objeto de discussão de várias publicações,

\footnotetext{
NOTAS

${ }^{5} \mathrm{~A}$ analogia não se aplica, evidentemente, em todos os aspectos. Por um lado, a tradução é uma atividade profissional e, por conseguinte, a questão da competência é relevante aqui.

${ }^{6}$ Isto não é necessariamente verdade para outras partes do mundo. Muitos linguistas árabes, por exemplo, ainda afirmam que as variedades faladas de árabe são inferiores, não valem a pena estudar, e alguns até insistem que o árabe falado não tem regras!

${ }^{7}$ O corpus finlandês era de aproximadamente três milhões de palavras de finlandês original e três milhões de palavras de finlandês traduzido em junho de 1999. Consiste em textos completos publicados após 1995 e pertencentes a três gêneros: escrita acadêmica, ficção e literatura infantil. As línguas de origem para a seção de tradução do corpus são restritas ao inglês, alemão e russo.
} 
em particular (LAVIOSA, 1996; BAKER, 1996b. KENNY, 1999), embora ainda haja muito a ser feito nessa área também.

\subsection{O Translational English Corpus}

O Translational English Corpus (http://genealogiesofknowledge.net/tec/) é um corpus de TTs para o inglês partindo de uma grande variedade de línguas europeias e não europeias, e realizado no Centre for Translation Studies do UMIST (University of Manchester Institute of Science and Tehcnology). É composto por quatro subcorpora: ficção, biografia, notícias e revistas de bordo. A dimensão global do corpus no momento da escrita deste artigo é de 5,5 milhões de palavras; e deverá atingir vinte milhões de palavras até ao ano 2001. Este é um tamanho modesto, dado o desenho do corpus (especialmente em termos da variedade de línguas de origem). 0 corpus deveria, idealmente, ser ampliado para cinquenta milhões de palavras, tendo em conta os recursos adequados. 0 problema, como sempre, é garantir fundos suficientes para o projeto.

0 corpus pode ser acessado livremente na web, usando um conjunto de ferramentas básicas de software fornecidas no site e relevantes para permitir que o pesquisador execute concordâncias e listas de palavras ${ }^{8}$. Planos estão em andamento para melhorar a funcionalidade do software em um futuro próximo e para permitir que os usuários executem diferentes tipos de análises em um subconjunto selecionado do corpus. A gama de seleções a ser oferecida em primeira instância incluirá o seguinte:

- $\quad$ Seleção por TPs, ou seja, compilação apenas de textos traduzidos de uma língua específica, habilitando o analista a investigar a influência de uma língua fonte (LF) em especial sobre os padrões do inglês traduzido.

- Seleção por tradutor: o corpus é projetado para incluir vários textos produzidos por distintos tradutores individuais, tanto britânicos quanto

\footnotetext{
80 software e o site são desenvolvidos e mantidos por Saturnino Luz (luzs@acm.org). 0 software de concordância não funciona corretamente em todos os navegadores. Os utilizadores podem receber uma mensagem no sentido de que o servidor pode não estar ativo, caso em que podem descarregar um software separado, também disponível no site, para garantir o acesso direto ao software de concordância, independentemente do tipo de navegador utilizado.
} 
americanos (por exemplo, o falecido Giovanni Pontiero, Peter Bush, Carol Maier, Peter Clark). Este instrumental é projetado para permitir a verificação do estilo ou do padrão linguístico específico para tradutores individuais.

- $\quad$ Seleção por subcorpus: apenas ficção, apenas revistas de bordo etc.

Todos o software foi desenvolvido para acessar corpora também disponíveis gratuitamente na web, não só para uso no processamento do Translational English Corpus, mas também para serem baixados e usados para processar outros corpora aos quais os usuários podem ter acesso independente. Ao longo das pesquisas, uma versão independente da plataforma do software também será disponibilizada para a comunidade investigativa, tornando possível para os usuários executar o software em PCs, MACs, plataforma Unix, etc.

O Translational English Corpus é meticulosamente documentado em termos de características extralinguísticas, tais como gênero, nacionalidade e ocupação do tradutor, direção de tradução, língua de origem, editor do texto traduzido etc. Esta informação é mantida em um arquivo de cabeçalho separado para cada texto (Ver Apêndice 1 como exemplo de um arquivo de cabeçalho completo). 0 software de concordância é projetado para fornecer a informação no arquivo de cabeçalho disponível para o pesquisador em um piscar de olhos, como pode ser visto na Figura 1.

A razão pela qual nos demos ao trabalho, na UMIST, de documentar estas características extralinguísticas e disponibilizá-las prontamente aos investigadores é que não encaramos a Tradução como um fenômeno puramente linguístico, apesar da ênfase colocada na análise dos padrões de linguagem. Pelo contrário, somos da opinião de que a linguagem em geral, e a linguagem da Tradução em particular, refletem limitações que operam no contexto da produção e da recepção: esses constrangimentos são de natureza social, cultural, ideológica e, naturalmente, também cognitiva. Isto significa que, se identificarmos o que pensamos ser um padrão linguístico significativo, temos de ser capazes de o explicar (ou fornecer a motivação para isso) analisando os contextos típicos em que ocorre. No contexto dos Estudos da Tradução - mais que no da Linguística de Corpus - isto significa buscar por motivações que podem originar das escolhas individuais de um tradutor ou tipo de tradutor, relacionando um padrão ao impacto de uma LF ou examinando-o para ver se está associado a um tipo particular de TP e assim por diante. 


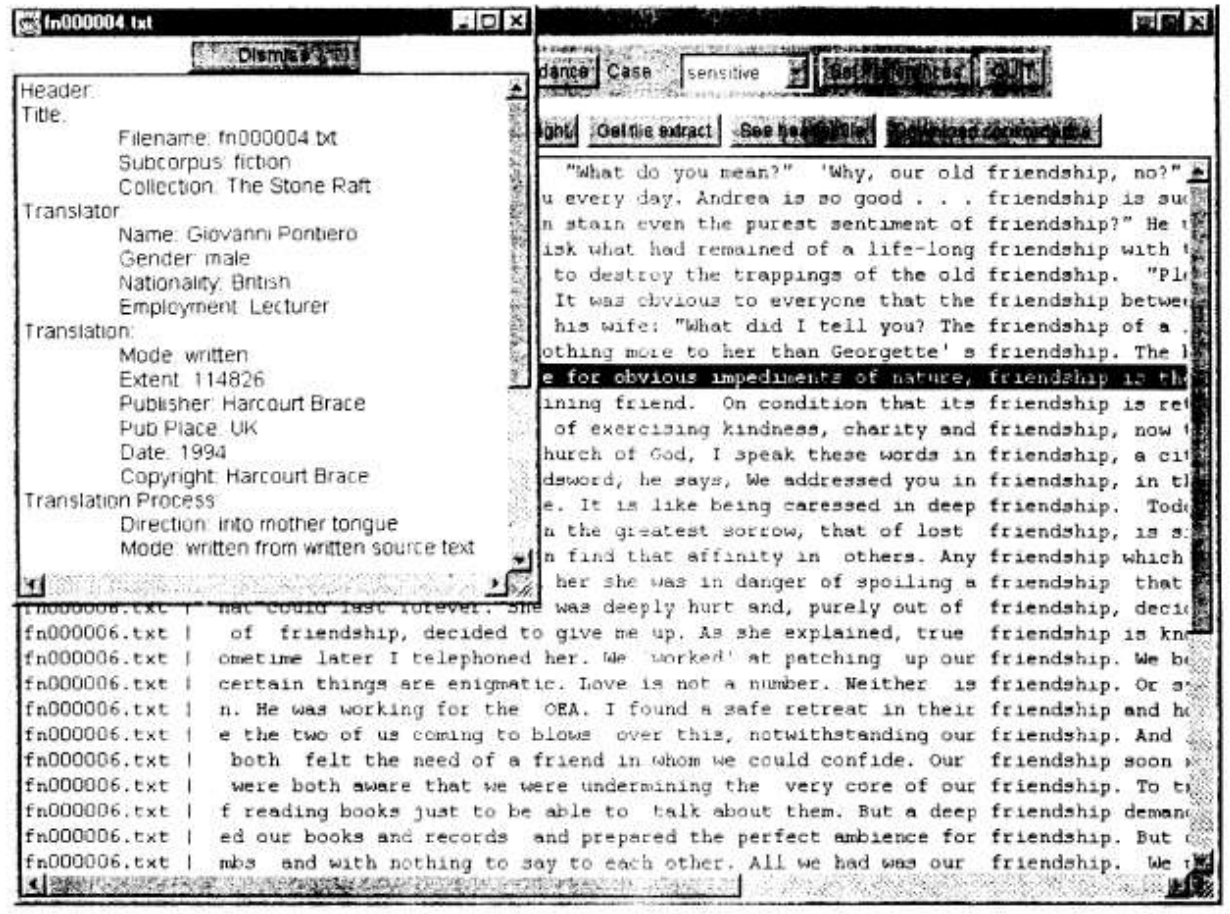

Figura 1: Imagem do cabeçalho

Aqui está um exemplo relativamente simples para ilustrar este ponto. 0 Apêndice 2 apresenta uma concordância da palavra gay no Translational English Corpus. Uma vez que eu não posso reproduzir o cabeçalho completo para cada uma das concordâncias e exibi-las aqui da mesma maneira como seriam exibidas na tela, eu listei, nos Apêndices, algumas das informações relevantes dos arquivos de cabeçalho. 0 padrão distinto aqui é restrito a um determinado tradutor, Lawrence Venuti, que defende o que chama de "estrangeirização" ou "minorização" das estratégias de tradução que visam interromper a experiência de leitura e direcionar a atenção dos leitores para a materialidade da língua e para o fato de que eles estão lendo uma tradução. Venuti, na verdade, menciona especificamente o uso de arcaísmos como uma estratégia para alcançar este efeito (ver, por exemplo, Venuti [1996]). Mas note-se também que todas as traduções destacadas por Venuti são de TPs que foram escritos entre o final dos anos 1800 e o início dos anos 1900, o que pode prover respostas para o uso distinto da palavra gay nessas traduções. Escusado será dizer que o padrão distintivo em questão diz respeito ao uso de gay no sentido obsoleto de "feliz" ou "alegre", em vez de seu atual sentido de "homossexual". 


\section{Um programa de investigação experimental para os Estudos da Tradução Baseados em Corpus}

Embora a aplicação das técnicas de corpus ao Estudo da Tradução seja um fenômeno muito recente, várias teses de doutoramento já foram concluídas neste domínio, tendo sido também dedicadas várias publicações ao tema, embora nem todas estejam estritamente orientadas para a Tradução. Por exemplo, embora o recente volume editado por Stig Johansson e Signe Oksefjell, sob o título de Corpora and CrossLinguistic Research (JOHANSSON, OKSEFJELL, 1998), faça algumas referências aos Estudos da Tradução, muito dele é, essencialmente, sobre o uso de corpora em Linguística Contrastiva. A conhecida revista de Tradução Meta, por outro lado, dedicou uma edição completa ao tema (LAVIOSA, 1998a) sob o título The Corpus-based Approach. E, significantemente, a edição carrega um artigo de Maria Tymoczko, uma das principais teóricas da Tradução e alguém que nunca esteve envolvido neste tipo de trabalho. 0 artigo discute o significado da pesquisa baseada em corpus para o futuro dos Estudos da Tradução como uma disciplina e descreve alguns de seus pontos fortes e perigos potenciais. 0 que isto significa é que os Estudos da Tradução Baseados em Corpus, como se sabe, são agora um paradigma importante na área, um paradigma que envolve a atenção dos principais estudiosos, quer estejam ou não envolvidos na investigação baseada em corpus.

Mas o que é que a investigação de Tradução baseada em corpus tenta alcançar? A que tipo de agenda é que ela se fixou? A resposta simples para isso é que a pesquisa baseada em corpus dentro dos Estudos da Tradução tem tantas agendas como existem pesquisadores trabalhando com corpora. 0 campo já é extremamente diversificado, com diferentes pesquisadores e professores de Tradução desenvolvendo suas próprias agendas e metodologias. Alguns têm em mente aplicações estritamente práticas ou pedagógicas, que envolvem essencialmente a utilização de corpora como recurso para a preparação de materiais didáticos em programas de formação de tradutores ou a utilização de corpora num ambiente de aprendizagem de língua assistida por computador, isto é, como auxílio à aquisição ou à verificação de novos padrões ora em LF ora em língua meta (LM), ou a verificação dos padrões de compatibilidade entre as duas línguas a fim de realizar escolhas apropriadas na tradução. Isto é particularmente útil 
em situações em que os estudantes são ensinados a traduzir para uma língua estrangeira e, portanto, não podem confiar na sua intuição para decidir se algo soaria natural na LM ou não.

Outros, como eu, estão mais interessados em usar corpora para realizar diversos tipos de estudos teóricos ou descritivos. Em última análise, o que os investigadores interessados em questões teóricas querem ser capazes de fazer é desenvolver um quadro que possa explicar a interação entre três fenômenos: as expectativas do público, as suposições ou reivindicações do teórico e a prática real dos tradutores profissionais. A questão geral é: que tipo de relação existe (se de fato existe) entre o que o público espera que os tradutores produzam, o que o teórico pensa que os tradutores produzem e o que os tradutores realmente produzem? Este ramo dos Estudos da Tradução Baseados em Corpus que escolhi para o foco neste artigo pode direcionar a análise, em primeira instância, às declarações do público (por exemplo, revisores, no caso de ficção) e às declarações do teórico contra o registro de prática tradutória real refletida no corpus. Vou deixar de lado a questão de examinar as expectativas do público, para ser abordada talvez em outro artigo, e vou tentar explicar, em vez disso, o que significa usar corpora para examinar a validade de declarações teóricas sobre Tradução.

Os analistas da Tradução, de um modo geral, assumem que a linguagem na tradução é consistentemente diferente da linguagem original, e essas suposições são refletidas em uma variedade de afirmações feitas na literatura. Às vezes, as declarações são globais, feitas para se aplicar a todas as línguas traduzidas, e algumas vezes, eles se concentram em particular no inglês traduzido. Aqui estão alguns exemplos de afirmações teóricas que valem a pena investigar em grande escala, para ver se as afirmações do teórico são corroboradas pelos dados.

Anthony Pym afirma em seu livro Oxford Guide to Literature in English Translation que:

As traduções para o inglês tendem a ser em uma língua que é menos específica, mais internacional do que a maioria das obras originalmente escritas em inglês. As traduções para crianças, para citar um exemplo, raramente têm o sabor de um inglês regional (embora todas as infâncias sejam regionais), simplesmente porque tradutores e editores propuseram-se a se dirigir a muitas regiões ao mesmo tempo (PYM, no prelo ${ }^{9}$ ).

\footnotetext{
${ }^{9}$ A obra foi publicada em 2000.
} 
Encontramos exemplos semelhantes no trabalho de Gideon Toury. Por exemplo, uma das normas sugeridas pelo autor (1995, p. 268) salienta que “(...) na tradução, as relações textuais que se obtêm no original são muitas vezes modificadas, às vezes ao ponto de serem totalmente ignoradas, a favor de opções (mais) habituais oferecidas por um repertório alvo".

Em outras palavras, Toury afirma que os tradutores tendem a manter padrões seguros e típicos da LM e ignorar inovações ou, por exemplo, repetições de palavras-chave que podem servir uma função de coesão no TP.

Estes são exemplos muito breves do tipo de afirmações feitas sobre tradução que gostaríamos de investigar em grande escala e com muito mais precisão, utilizando as técnicas de análise de corpus. Eles são típicos da maioria das afirmações teóricas feitas sobre a natureza da Tradução até agora: altamente abstrato, com pouca ou nenhuma indicação de como a investigação das hipóteses pode ser prosseguida em termos concretos. A fim de testar uma declaração como a de Pym, por exemplo, temos que especificar o que significa para o inglês traduzido ser menos específico do que o inglês original. Basear-nos íamos em um vocabulário mais restrito, por exemplo? Seria de se esperar que em uma lista de palavras de um corpus de inglês traduzido fossem incluídas menos palavras dialetais, com menor frequência, do que em uma lista de palavras de um corpus semelhante de inglês original? Podemos esperar padrões semelhantes de simplificação em termos de estruturas sintáticas, tais como cláusulas compostas vs. complexas, ou até mesmo no tocante aos tamanhos das frases?

Por vezes, as afirmações feitas por diferentes teóricos podem ser contraditórias ou podem parecer contraditórias, porque a gama limitada de dados que até agora informou a nossa teoria torna difícil apresentar uma afirmação descritiva e especificar os contextos em que ela se aplica. Aqui está um exemplo para ilustrar tal perspectiva. Uma das chamadas normas da Tradução de Toury (1995, p. 278) baseia-se na alegação de que:

(...) a tolerância à interferência - e, portanto, a resistência de suas manifestações, tende a aumentar quando a tradução é conduzida de uma língua/cultura de maior ou mais alto prestígio, especialmente se a língua/cultura alvo é menor ou mais fraca em outros sentidos. 
Em termos gerais, e sem divagar em um exame crítico das noções problemáticas tais como "fraco" ou "menor" em relação às culturas e línguas, o que Toury está sugerindo aqui é que há sempre, em qualquer cultura, idiomas de origem e fonte de gêneros que são percebidos como de prestígio em relação ao ponto de vista da literatura alvo. Por exemplo, a filosofia alemã ou a teoria crítica francesa parecem ser consideradas como prestigiosas no mundo anglo-americano de hoje. Traduções de obras originárias dessas línguas e pertencentes a esses gêneros, Toury observa, são susceptíveis a priorizar princípios como fidelidade e precisão e se concentrar menos na naturalidade da expressão do ponto de vista da cultura alvo. E essas estratégias, que se manifestam em um nível mais elevado de interferência no TT, serão toleradas pelo público de chegada por causa do status da LF e do TP.

Curiosamente, Robinson (1997, p. 31-32), seguindo Jacquemond (1992), faz uma afirmação muito diferente, a qual parece, pelo menos à superfície, contradizer a norma da interferência de Toury:

Quando uma cultura hegemônica (...) traduz as obras produzidas pela cultura dominada; essas obras serão vistas e apresentadas como difíceis, misteriosas, inescrutáveis, Esotéricas e necessitadas de um pequeno grupo de intelectuais para as interpretar, enquanto uma cultura dominada traduzirá as obras de uma cultura hegemônica de maneira mais acessível às massas.

Isto parece estar sugerindo o oposto do que Toury afirma, porque (presumivelmente) a percepção de "dificuldade" deve — pelo menos parcialmente — ser alcançada por meio da adoção de certas estratégias de tradução que favorecem a literalidade em oposição à fluência. Se, como Robinson sugere, culturas "hegemônicas", "dominantes", "fortes" ou "grandes" (chame como quiser) apresentarem obras pertencentes às culturas "dominadas", "fracas", "menores" como difíceis e incompreensíveis, adotando, ou até mesmo, parodiando as estratégias, como estas diferirão na adoção de iguais ou semelhantes estratégias de tradução de textos de idiomas de origem/gêneros "de prestígio"? Além disso, a última parte da declaração é difícil de ser aceita ao mesmo tempo que a norma de interferência de Toury. Uma cultura "dominada" não consideraria uma cultura "hegemônica" como prestigiosa, e isto não deveria significar — de acordo com a norma de 
Toury — que traduziria as obras de uma cultura/língua tão "prestigiada" mais literalmente, com um nível mais elevado de interferência, em vez de "acessível para as massas"?

Uma maneira de esclarecer tal "confusão" teórica é examinar traduções, digamos, para o inglês, a partir de LFs ou gêneros que nossos teóricos assumem serem percebidos como prestigiosos no mundo anglo-americano, para ver se eles mostram consistentemente traços de proeminência na forma de tipos específicos de padronização linguística. Ao mesmo tempo, seria necessário estudar traduções para o inglês a partir de línguas/gêneros de origem que mais uma vez - alguns teóricos assumem serem percebidas como "menos prestigiadas", por exemplo, literatura árabe moderna (ver Said [1990]), para estabelecer se e como o seu padrão difere do padrão de traduções das chamadas línguas/gêneros "prestigiados" e de outras traduções em geral. Isto promete ser um processo confuso, especialmente em vista da imprecisão das noções usadas na formulação de muitas declarações teóricas sobre Tradução hoje ("fraco", "menor", "dominado" etc.). Mas, pelo menos, o acesso a um grande corpus de TTs, como o Translational English Corpus, deve fornecer-nos um ponto de partida para afiar as nossas declarações teóricas durante o seu teste em termos concretos e à luz de um volume substancial de dados autênticos.

\subsection{Centrar a atenção na diversidade dentro de um corpus de traduções}

Línguas traduzidas (dentro de um determinado contexto histórico e social) podem ter certas características que as distinguem das línguas originais, mas se isto prova ou não ser o caso, é importante não restringir-nos a esta questão específica, mas tentar também considerar a diversidade na tradução do corpus propriamente dito. Além de testar a validade das declarações teóricas do tipo discutido acima, nós também queremos ir além de comparar linguagem original e traduzida em geral e fazer perguntas mais específicas que podem abordar a diversidade que é inerente em qualquer área de uso da linguagem, incluindo a tradução. Por exemplo, podemos fazer perguntas como:

- Os tradutores homens ou mulheres empregam diferentes estratos de tradução ou produzem um tipo diferente de linguagem quando traduzem?

- $\quad$ Os padrões de fluência/altos níveis de legibilidade em oposição ao uso 
consciente de padrões linguísticos desconhecidos/criativos variam não só entre tradutores individuais, mas possivelmente também entre diferentes tipos de editores? Em outras palavras, o perfil da casa editorial tem impacto na composição linguística de uma tradução? Há numerosos pequenos editores dedicados com uma agenda cultural — como Dedalus ou Blood Axe no Reino Unido e editoras universitárias, como a University of Nebraska Press na América - que trazem um monte de traduções, por vezes especializadas em línguas de origem específica. Será que esses editores não só escolhem livros diferentes para traduzir, mas também desenvolvem políticas e atitudes diferentes em relação à tradução de editores tradicionais como Penguin ou Harper Collins, que têm como alvo um público leigo? Em caso afirmativo, essas políticas podem ser refletidas no padrão linguístico das traduções que publicam (e que, claro, editam antes da publicação).

- Certas características ou estratégias linguísticas são mais propensas a ocorrer em certos tipos de gêneros de tradução, como ficção traduzida, notícias, revistas infantis?

- Qual é o impacto da LP?

É particularmente importante desenvolver uma metodologia para investigar a capacidade de tradução. Se nós observamos, como tem sido frequentemente afirmado, que as traduções são em grande parte conservadoras em sua "maquiagem" linguística, que tende a manter uma margem de segurança, padrões típicos da LM, claramente, isto não significa que todas as traduções de todos os gêneros optam por padrões "seguros" e coibem a criatividade. Como Kenny (1999) mostrou em relação às traduções inglesas da literatura experimental contemporânea alemã, alguns tradutores são muito mais propensos a usar a LM criativamente, em vários níveis: eles consistentemente compõem metáforas incomuns, compostos inovadores, usam sintaxe incomum, e assim por diante. Estes tradutores destacam-se num corpus e são muito individuais em suas estratégias. É essencial estudar e explicar o comportamento criativo de tais tradutores, apenas porque o corpus de seus trabalhos é algo percebido pelos Estudos da Tradução como centrando-se exclusivamente em regularidades e ignorando padrões únicos ou atípicos. Esta percepção está claramente errada: é precisamente porque os corpora nos permitem estabelecer regularidades que podemos identificar o incomum ou o estado em termos explícitos do que é exatamente incomum ou criativo sobre ele. 


\section{Considerações Finais}

Estudiosos de Tradução interessados em elaborar uma descrição da linguagem traduzida estão tentando mudar sua percepção como "desviante", desenvolvendo uma metodologia coerente para identificar suas características distintivas e relacionando esta descrição a um conjunto de restrições e motivações que influenciam o comportamento tradutório. A disponibilidade de técnicas desenvolvidas pelas Linguística de Corpus fornece um ponto de partida razoável para este tipo de pesquisa, mas a metodologia para avaliar um corpus com o objetivo de verificar a validade das abstrações teóricas precedentes ainda precisa ser desenvolvida. Além disso, pesquisadores devem tomar cuidado para não confundir seu objeto de investigação dentro dos Estudos da Tradução - ou mesmo reduzi-lo com aquele da Linguística de Corpus. Uma descrição detalhada das características linguísticas não é um fim em si para a tradução acadêmica: ela é meramente um meio para um fim, um primeiro passo para a compreensão das pressões e restrições sob as quais os tradutores operam e que, inevitavelmente, deixam traços na língua que eles produzem. 
APÊNDICE 1. CABEÇALHO DA AMOSTRA APRESENTADO NA TELA DE CONCORDÂNCIA

\begin{tabular}{ll} 
TITLE & \\
Filename: & fn000039.txt \\
Subcorpus: & fiction \\
Collection: & Mothballs \\
TRANSLATOR & \\
Name: & Peter Theroux \\
Gender: & male \\
Nationality: & American \\
Employment: & Translator \\
Status: & part-time; free-lancer \\
TRANSLATION & \\
Mode: & written \\
Extent: & 58200 \\
Publisher: & Garnet \\
Place: & UK \\
Date: & 1996 \\
Copyright: & Peter Theroux \\
Sponsor: & The Arts Council of England \\
Comments: & In Arab Women Writers Series \\
TRANSLATION PROCESS & \\
Direction: & into mother tongue \\
Mode: & Written \\
Type: & full \\
AUTHOR & \\
Name: & Alia Mamdouh \\
Gender: & female \\
Nationality: & Iraqi \\
SOURCE TEXT & \\
Language: & Arabic \\
Mode: & written \\
Status: & original \\
Publisher: & al-Hay'a al-Masriah al-Amah li-al-Kitab \\
Place: & Egypt \\
Date: & 1985 \\
\hline
\end{tabular}




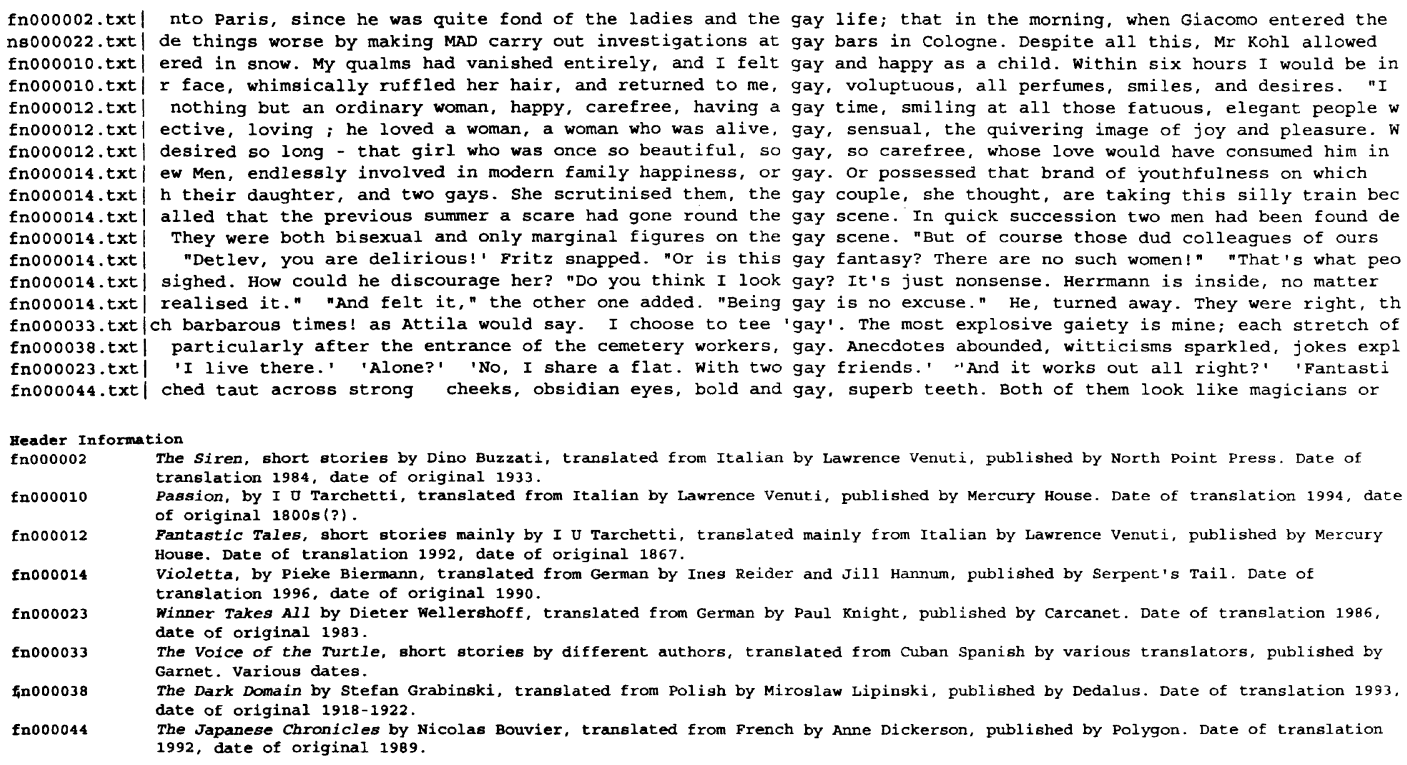

ns000022 tot de thins fn000010.txt ered in snow. My gualms had vanished entirely, and I felt gay and happy as a child. within six hours I would be in fn000010.txt | r face, whimsically ruffled her hair, and returned to me, gay, voluptuous, all perfumes, smiles, and desires. "I fnoovo12.xt nothing but an ordinary woman, happy, fn000012.txt | desired so long - that girl who was once so beautiful, so gay, so carefree, whose love would have consumed him in fno00014 txt ew Men, endlessly involved in modern family happiness, or gay. Or possessed that brand of youthfulness on which nno00014.txt / h their daughter, and two gays. She scrutinised them, the gay couple, she thought, are taking this silly train bec fno fno00014.txt "Detlev, you are delirious!' Fritz snapped. "Or is this gay fantasy? There are no such women!" "That's what peo fn000014.txt sighed. How could he discourage her? "Do you think I look gay? It's just nonsense. Herrmann is inside, no matter fno00014.txt realised it." "And felt it," the other one added. "Being gay is no excuse." He, turned away. They were right, th ( fno00023.txt particularly after the entrance of the cemetery workers, gay. Anecdotes abounded, witticisms sparkled, Joks ast fno00044.txt ched taut across strong cheeks, obsidian eyes, bold and gay, superb teeth. Both of them look like magicians or

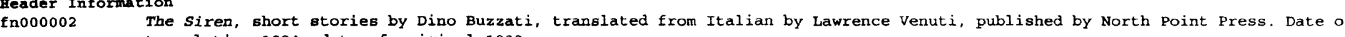
fno00010 Passion, by I O Tarchetti, translated from Italian by Lawrence venuti, published by Mercury House. Date of translation 1994, date Violets, by pieke date or original 1990 .

fn000038 The Dark Domain by Stefan Grabinski, translated from Polish by Miroslaw Lipinski, published by Dedalus. Date of translation 1993. fno00044 date of original 1918-1922.

1992, date of original 1989 .

\section{REFERÊNCIAS}

AARTS, J. Introduction. In: JOHANSSON, S.; OKSEFJELL, S. (Eds.), Corpora and CrossLinguistic Research. Theory, Method, and Case Studies. Amsterdam and Atlanta: Rodopi, 1998, p. ix-xiv.

BAKER, M. Linguistic Perspectives on Translation. In: FRANCE, P. (Ed.), The Oxford Guide to Literature in English Translation. Oxford: Oxford University Press., 2000.

Linguística e estudos culturais: paradigmas complementares ou antagônicos nos estudos da tradução?" In: MARTINS, M.A.P. (Ed.) Tradução e Multidisciplinaridade. Rio de Janeiro: Editora Lucerna, 1999, p. 15-34.

Reexplorer la langue de la traduction: une approche par corpus. , 1998.

Linguistics and Cultural Studies: Complementary or Competing Paradigms in Translation Studies? In: LAUER, A.; GERZYMISCH-ARBOGAST, H.; HALLER, J.; STEINER, E. (Eds.) Ubersetzungswissenschaft im Umbruch. Tubingen: Gunter Narr, p, 9-19, 1996a.

Corpus-based Translation Studies: The Challenges that Lie Ahead. In: SOMERS, H. (Ed.) Terminology, LSP and Translation: Studies in Language Engineering, in Honour of Juan C. Sager. Amsterdam and Philadelphia: John Benjamins, p. 175-186, 1996b. 
Corpora in Translation Studies: An Overview and Some Suggestions for Future Research. Target 7(2), p. 223-243, 1995.

Corpus Linguistics and Translation Studies: Implications and Applications. In: BAKER,M.; FRANCIS, G.; TOGNINI-BONELLI, E. (Eds.) Text and Technology: In Honour of John Sinclair. Amsterdam and Philadelphia: John Benjamins, p. 233-250, 1993.

JACQUEMOND, R. Translation and Cultural Hegemony: The Case of French-Arabic Translation. In: VENUTI, L. (Ed.) Rethinking Translation. London and New York: Routledge, p. 139-158, 1992.

JOHANSSON, S.; OKSEFJELL, S. (Eds.). Corpora and Cross-Linguistic Research. Theory, Method, and Case Studies. Amsterdam and Atlanta: Rodopi, 1998.

KENNY, D. (Ab)normal Translations: a German-English Parallel Corpus for Investigating Normalization in Translation. In: LEWANDOWSK-TOMASZCZYK, B.; MELIA, P.J. (Eds.), Practical Applications in Language Corpora. PALC '97 Proceedings. Lódz: Lódz University Press, p. 387-392, 1997.

Norms and Creativity: Lexis in Translated Text. PhD Thesis,Manchester: Centre for Translation Studies, Department of Language Engineering, UMIST, 1999.

LAVIOSA, S. (Ed.) L'Approche basee sur le corpus/The Corpus-based Approach. Special Issue of Meta 43(4), 1998a.

The English Comparable Corpus: A Resource and a Methodology. In: BOWKER, L.; CRONIN, M.; KENNY, D.; PEARSON, J. (Eds.) Unity in Diversity: Current Trends in Translation Studies. Manchester: St. Jerome Publishing, 1998b.

. How Comparable Can Comparable Corpora Be? Target 9(2), p. 289-319, 1997.

The English Comparable Corpus (ECC): A Resource and a Methodology for the Empirical Study of Translation. PhD Thesis. Manchester: Department of Language Engineering, UMIST, 1996.

Comparable Corpora: Towards a Corpus Linguistic Methodology for the Empirical Study of Translation. In: THELEN, M.; LEWANDOSKA-TOMASZCZYK (Eds.) Translation and Meaning (Part 3). Maastricht: Hogeschool Maastricht, 1995.

OLOHAN, M.; BAKER, M. Forthcoming. Reporting that in Translated English: Evidence for Subconscious Processes of Explicitation." Across Languages and Cultures. v. 1, n. 2, p. 141$158,2000$.

PYM, A. Historical Development. In: FRANCE, P. (Ed.) The Oxford Guide to Literature in English Translation. Oxford: Oxford University Press, 2000. 
ROBINSON, D. Translation and Empire. Postcolonial Approaches Explained. Manchester: St. Jerome Publishing, 1997.

SAID, E. Embargoed Literature. The Nation September 17, p. 278-280, 1990.

SINCLAIR, J. The Search for Units of Meaning. Textus IX, p. 75-106, 1996a.

Preliminary Recommendations on Corpus Typology. Eagles Web Site, ocument EAG-TCWG-CTYPIP, 1996b.

TOURY, G. Descriptive Translation Studies - and Beyond. Amsterdam and Philadelphia: John Benjamins, 1995.

\section{Biografia das tradutoras}

Talita Serpa é bacharel em Letras com Habilitação em Tradução pela Universidade Estadual Paulista Júlio de Mesquita Filho (2009), graduada em Ciências Sociais pela Universidade Federal de São Carlos (2004), mestre em Estudos da Tradução pela Universidade Estadual Paulista Júlio de Mesquita Filho (2012) e doutora em Estudos da Tradução pela Universidade Estadual Paulista Júlio de Mesquita Filho IBILCE (2017). Atualmente é pós-doutoranda da Universidade Estadual Paulista Júlio de Mesquita Filho (IBILCE).

Diva Cardoso Camargo é doutora em Tradução pela Universidade de São Paulo (1993), tem pósdoutorado em Estudos da Tradução por The University of Manchester (2003), é livre-docente em Estudos da Tradução pela Universidade Estadual Paulista Júlio de Mesquita Filho (2005). Atualmente é professora Adjunto-MS5, aposentada da Universidade Estadual Paulista Júlio de Mesquita Filho, campus de São José do Rio Preto, onde atua como professora voluntária e faz parte do corpo de docentes permanentes dos Programas de Pós-Graduação em Letras e Estudos Linguísticos. 